\title{
OLHARES SOBRE A CIDADE, A ARTE E A HISTÓRIA: EXPERIÊNCIAS ETNOGRÁFICAS NO ESPAÇO URBANO
}

\author{
Denise Alves da Costa Azeredo ${ }^{1}$ \\ Giovanna Aparecida Lisboa Dai-Prá \\ Letícia Moraes Marques ${ }^{3}$
}

\section{Introdução}

O presente relato resulta das experiências etnográficas construídas por três mestrandas do Programa de Pós Graduação em Processos e Manifestações Culturais da Universidade Feevale. Possuindo formação em áreas distintas da Antropologia, começaram a tecer seus conhecimentos antropológicos durante a disciplina de Concepções de Cultura e Manifestações Culturais, ministrada pela professora Ana Luiza Carvalho da Rocha. Ao longo dos estudos teóricos acerca da Cultura, da etnografia etnologia, surgiu a proposta de realizar um trabalho etnográfico de rua que possibilitasse conhecer o trabalho de campo e relacionar com os estudos teóricos.

Dentro da proposta para o trabalho, optou-se por investigar a interação entre um estúdio de tatuagem e um dos pontos principais no centro da cidade de Novo Hamburgo: a Tattoo Arte, localizada na Galeria Hamburguesa - Rua David Canabarro, 47, Centro, sendo esse um dos estúdios de tatuagem mais antigos de Novo Hamburgo, fundado em 1998, desde o seu início está presente no mesmo local, presenciando as transformações urbanas e sociais na região.

Ponto importante para a cultura, o lazer e o comércio da cidade, a Galeria Hamburguesa está localizada em uma rua movimentada, entre a avenida Pedro Adams Filho e a rua Bento Gonçalves, duas das principais ruas da cidade, onde é possível

\footnotetext{
${ }^{1}$ Universidade Feevale, Brasil. Email: dacadenise@,hotmail.com ORCID id: https://orcid.org/0000-0001-9773-5852

${ }^{2}$ Universidade Feevale, Brasil. Email: gi.ldaipra@gmail.com ORCID id: https://orcid.org/0000-0002-1543-5926

${ }^{3}$ Universidade Feevale, Brasil. Email: leticia_m_marques@hotmail.com ORCID id: https://orcid.org/0000-0003-0722-0877
} 
encontrar as maiores lojas de varejo do centro e alguns dos prédios com a arquitetura mais antiga. Em direção à Avenida Pedro Adams Filho há a Praça do Imigrante, o paradão, as "bancas" e a Casa da Artes. Na rua Bento Gonçalves, perto da rua David Canabarro, encontra-se a Igreja Evangélica de Confissão Luterana Ascensão (inaugurada em 1951), consultórios, bancos e a Escola IENH - Unidade Oswaldo Cruz. O Calçadão Oswaldo Cruz fica localizado atrás da Tattoo Arte e também possui acesso à Galeria Hamburguesa, lojas de varejo, lanchonetes e o Espaço Cultural Albano Hartz. A rua David Canabarro, onde se localiza o estúdio da Tattoo Arte, é cercada por lojas, lanchonetes e cafés, com antigos estabelecimentos, duas galerias e edifícios, cafeterias, a Universidade Aberta do Brasil - UAB - Polo Novo Hamburgo, o Procon, a Secretaria de Desenvolvimento Social, entre outros.

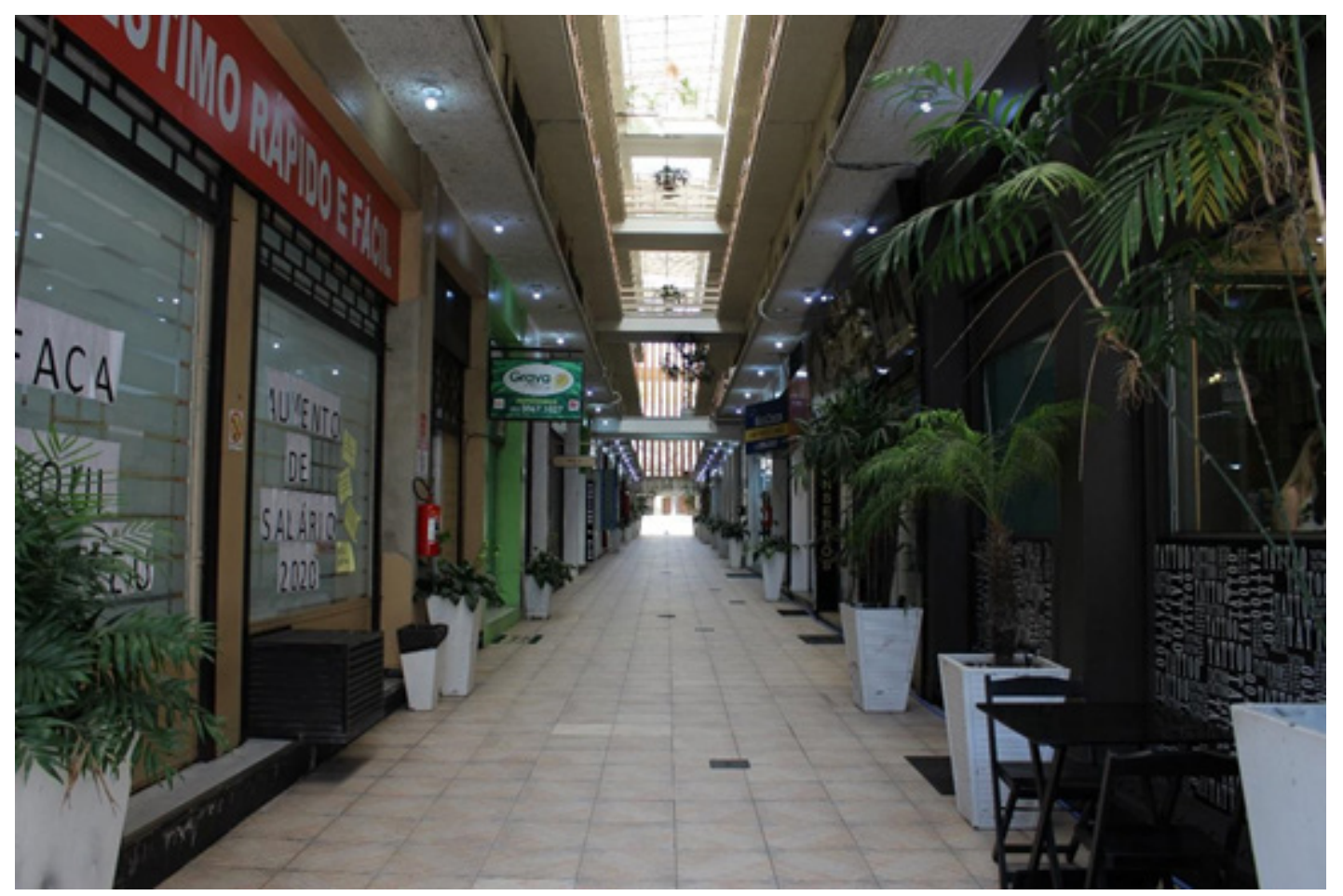

Fonte: Giovanna Dai-Prá (2020) - Galeria Hamburguesa, da rua David Canabarro em direção ao calçadão. 


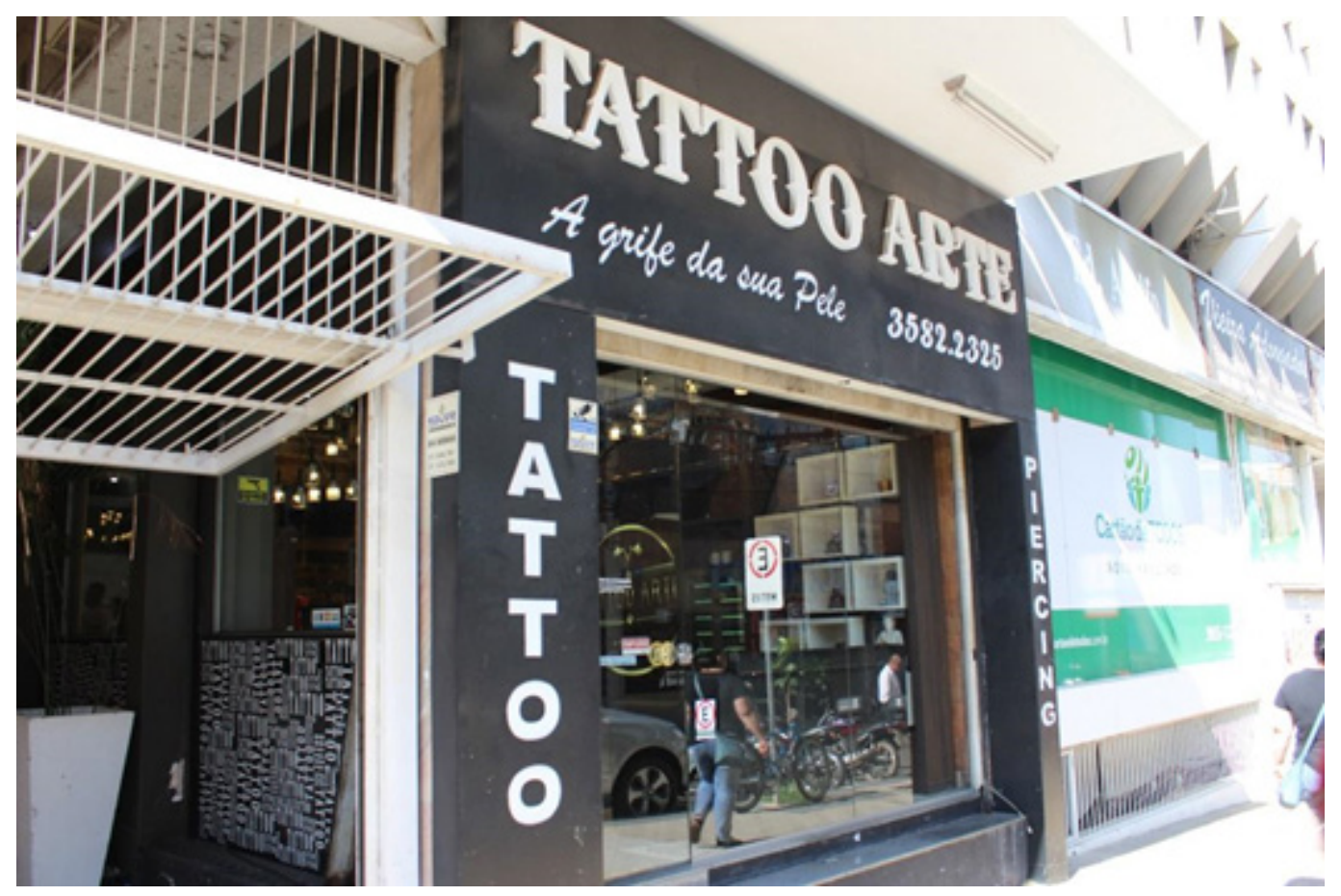

Fonte: Giovanna Dai-Prá (2020) - Galeria Hamburguesa, frente da Tattoo Arte, na rua David Canabarro.

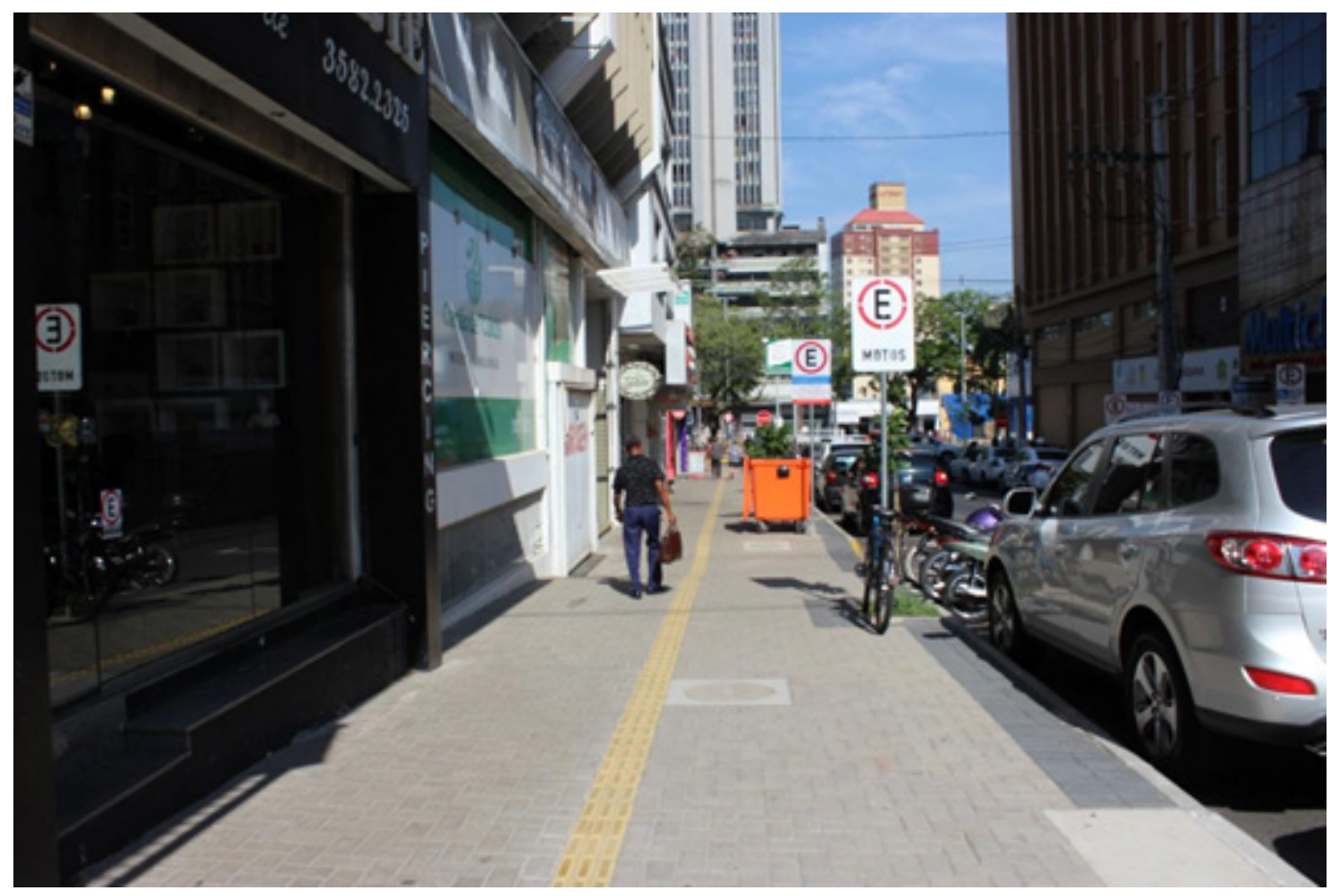

Fonte: Giovanna Dai-Prá (2020) -Frente da Tattoo Arte, na rua David Canabarro, em direção à Avenida Pedro Adams Filho. 


\section{Planejamento e saída à Campo.}

A realização da pesquisa iniciou com a delimitação do local objeto de estudo, escolhido por ser frequentado por uma das mestranda, a mestranda Denise. Após ser planejado os objetivos do trabalho, estes foram apresentados para a professora, que aprovou o projeto. Primeiramente foi organizado um grupo no whatsapp para dialogar sobre a estruturação do trabalho e em comum acordo foi decidido que a colega Denise iria fazer o primeiro contato com o proprietário do estúdio. Foi possível então marcar com o Jarbas, responsável pela agenda do estúdio, que no dia 13 de março de 2020, seria visitado o espaço e a redondeza.

Inicialmente, havia mais uma componente no grupo, mas que por questões de deslocamento e horário não pode continuar nesse projeto. Sendo assim, as alunas que permaneceram seus roteiros de saída de campo conforme explicado e exemplificado em aula. No dia 13 de março de 2020 - turno da manhã - as alunas deslocaram-se à Tattoo Arte. Denise saindo da Feevale-NH, Giovanna saindo de Estância Velha e Letícia saindo de Campo Bom, em direção a Novo Hamburgo.

Aproximadamente às $09 \mathrm{~h} 05 \mathrm{~min}$ encontraram-se em frente ao estúdio Tattoo Arte. Observamos que não havia sido organizado um roteiro de perguntas, surgiram alguns questionamentos quanto a realização do próprio trabalho de campo: como fazer as observações e entrevistar pessoas em um estabelecimento comercial? $\mathrm{O}$ dono concordou, mas e os outros funcionários? E os clientes? Diante disso, as perguntas foram realizadas conforme a entrevista fluía e felizmente a percepção inicial foi diferente do que se desenvolveu.

O primeiro contato foi com a equipe do estúdio. A Sabrina, gerente do local, se dispôs a dar entrevista e autorizou a gravar em áudio a fala dela. A gerente já havia sido avisada e se dispôs a responder nossas perguntas. A conversa foi conduzida por Denise e Letícia e no decorrer do diálogo a Giovanna foi realizando uma fotoetnografia do estúdio, com o objetivo de registrar o espaço e o ambiente. Com a análise de imagens, percebe-se a importância do material para uma melhor compreensão e interpretação da etnografia. Uma vez que é entendida como "uma gravação tangível da realidade, a mensagem visual toma-se uma prova material de se 'ter estado lá'" (Bittencourt 1994: 230). 


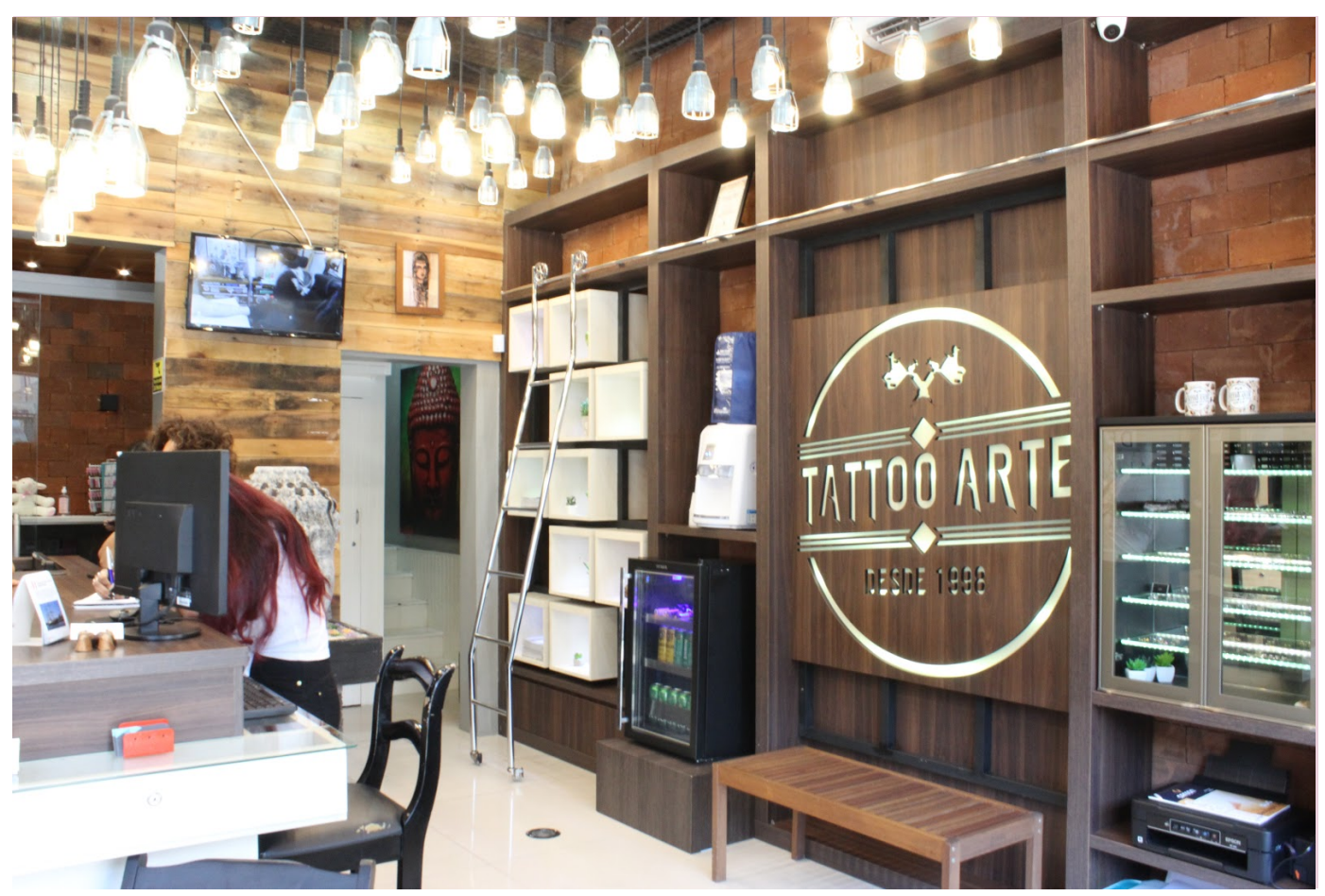

Fonte: Giovanna Dai-Prá (2020) -Recepção da Tattoo Arte.

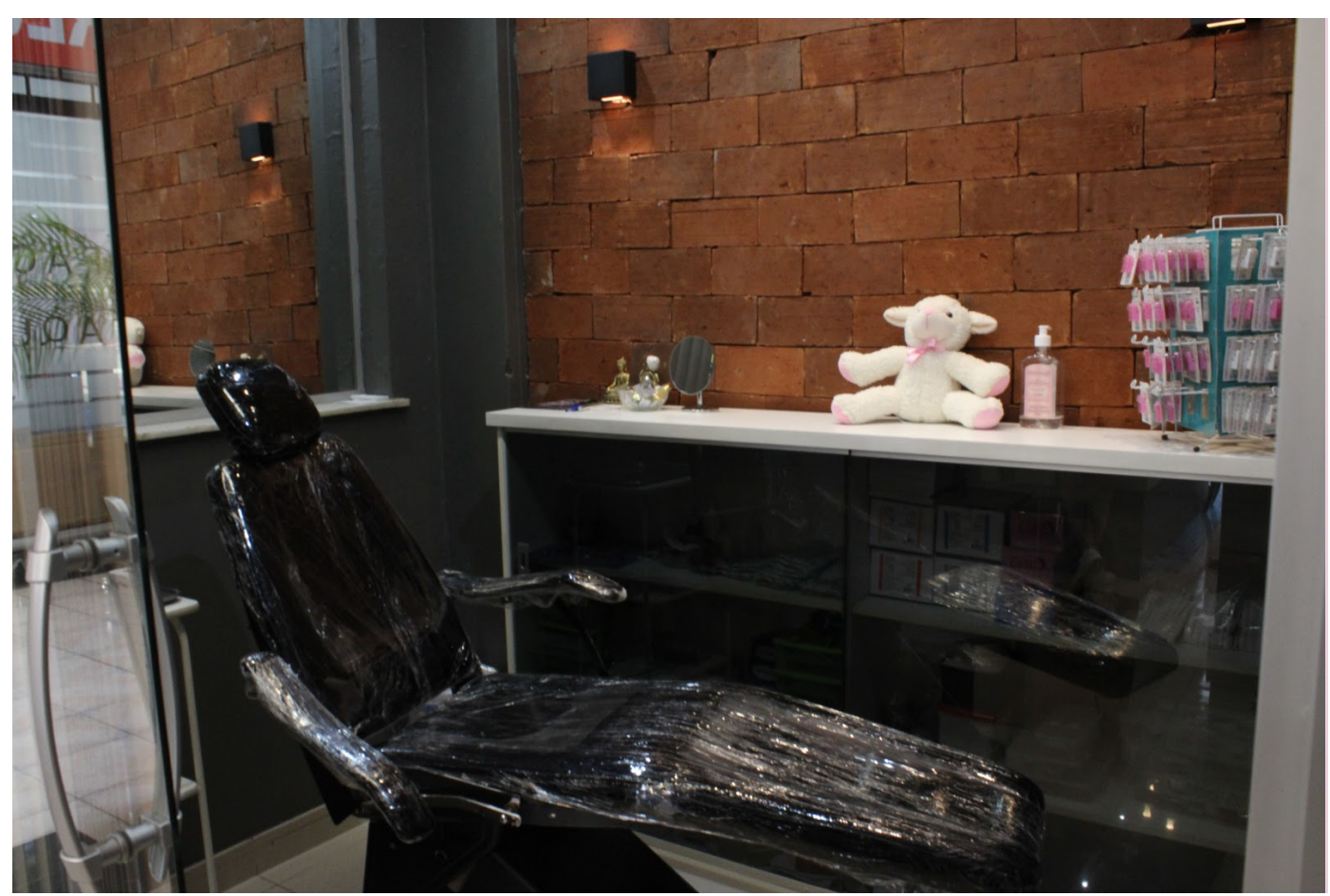

Fonte: Giovanna Dai-Prá (2020) - Sala de colocação de piercing .

Percebendo a curiosidade dos que estavam na recepção: Jarbas, a Ana (também funcionária), a Sabrina e um cliente que aguardava ser chamado, além da Pamela, uma tatuadora que havia iniciado no estúdio há duas semanas; a conversa foi tornada um 
pouco mais informal para que assim se sentissem mais à vontade para relatar e que fosse possível ouvir mais esses relatos como um depoimento e menos como um questionário. No decorrer da entrevista notou-se que os participantes estavam dispostos a contribuir e que permitiram facilmente o acesso ao estúdio.

Entretanto, observa-se também que a atenção recebida pode ter sido ocasionada pelo fato de que o proprietário é conhecido da Denise, uma vez que, segundo FooteWhite, relações pessoais criam maior aceitação do que apresentações e explicações. Durante a entrevista, foi possível desenvolver percepções sobre o ambiente, criando, recriando e mudando imagens pré-estabelecidas, além de perceber como é difícil fazer etnografia do que conhecemos ou que temos a pretensão de conhecer (de nós mesmos), como aponta Gilberto Velho ao afirmar que, [...]dentro de nossa própria sociedade existe, constantemente, esta experiência e estranhamento" (Velho, 1980: 16). Assim sendo, percebe-se que mesmo estando revestidas de "certezas" sobre o outro,

\footnotetext{
O que sempre vemos e encontramos pode ser familiar, mas não é necessariamente conhecido. No entanto estamos sempre pressupondo familiaridades e exotismos como fontes de conhecimento ou desconhecimento, respectivamente. (Velho; Viveiros de Castro, 1978: 11).
}

Segundo Roy Wagner, “[...] o antropólogo usa sua própria cultura para estudar outras, e para estudar a cultura em geral." (Wagner, 2017: 28), sendo assim, observou-se também que esse movimento foi tecido nos diários de campo sob diferentes perspectivas em relação às observações, e que os pontos de vista descritos refletem nossas vivências e formações acadêmicas: Denise, por ser artista e coreógrafa, observou muito a expressão corporal dos entrevistados, no início, durante e depois da nossa abordagem. Giovanna refletiu mais sobre características de quem frequenta o estúdio, tanto funcionários quanto os clientes, assim como suposições que carregava acerca da tatuagem e a sociedade, resolvidas com as entrevistas. Enquanto para Letícia, as atenções foram voltadas às formas de comunicação de cada entrevistado. Como por exemplo, a maneira que cada um procurava as palavras "certas" para explanar suas opiniões e depoimentos sobre a Tattoo Arte, buscando pela articulação adequada mesmo nos momentos em que a entrevista parecia menos formal. 


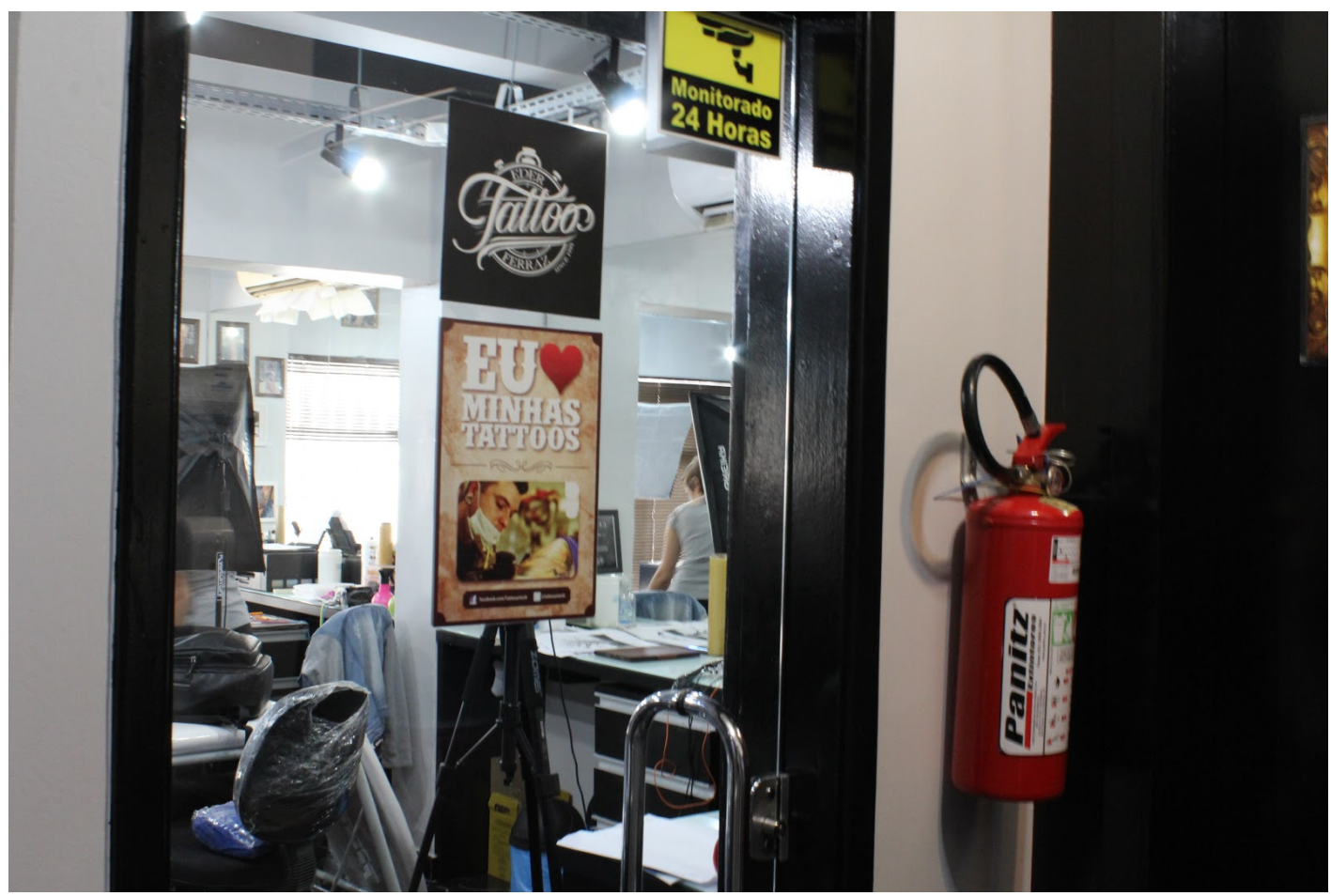

Fonte: Giovanna Dai-Prá (2020) - Sala de tatuagem .

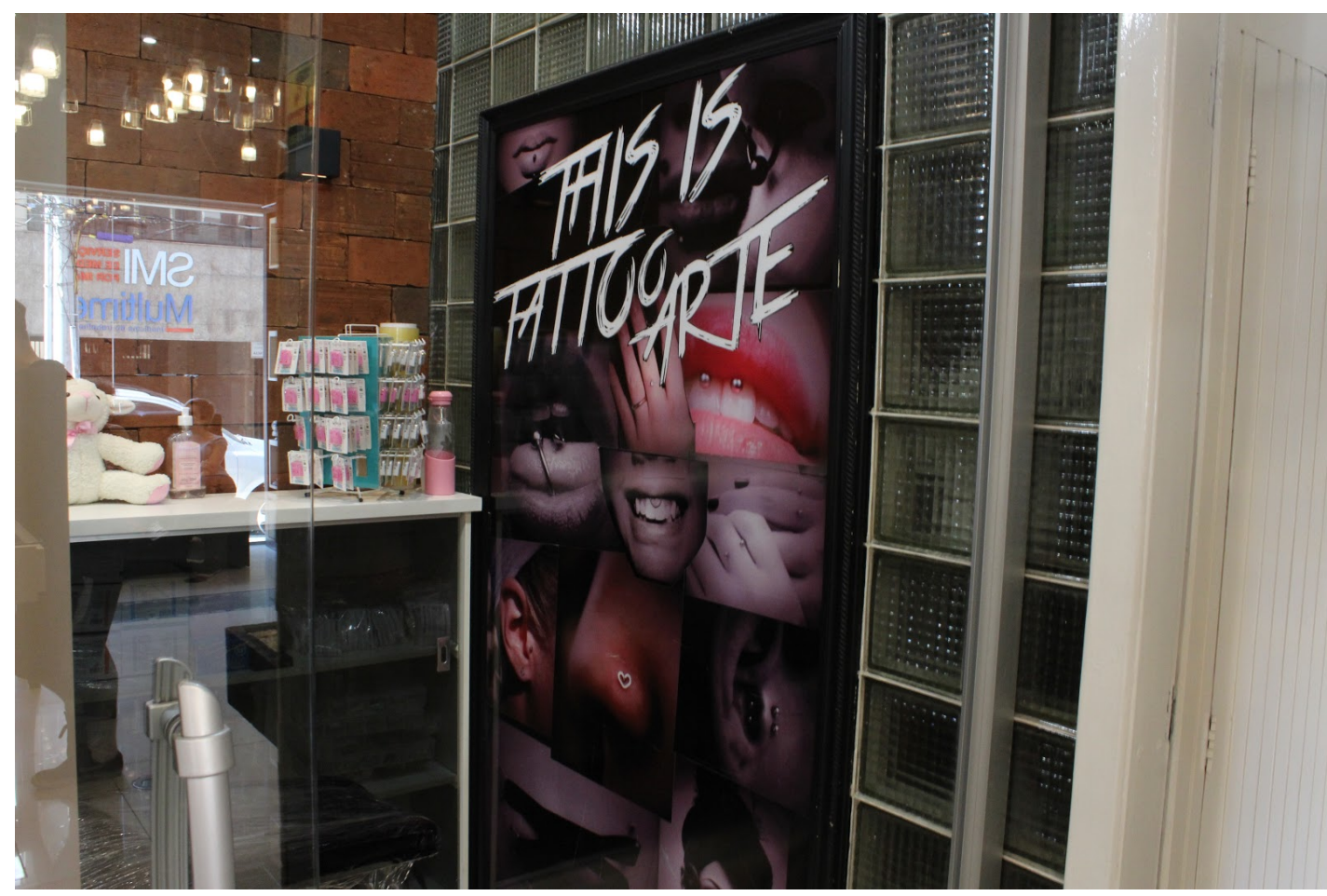

Fonte: Giovanna Dai-Prá (2020) - Sala de colocação de piercing, com exposição de modelos e trabalhos feitos . 


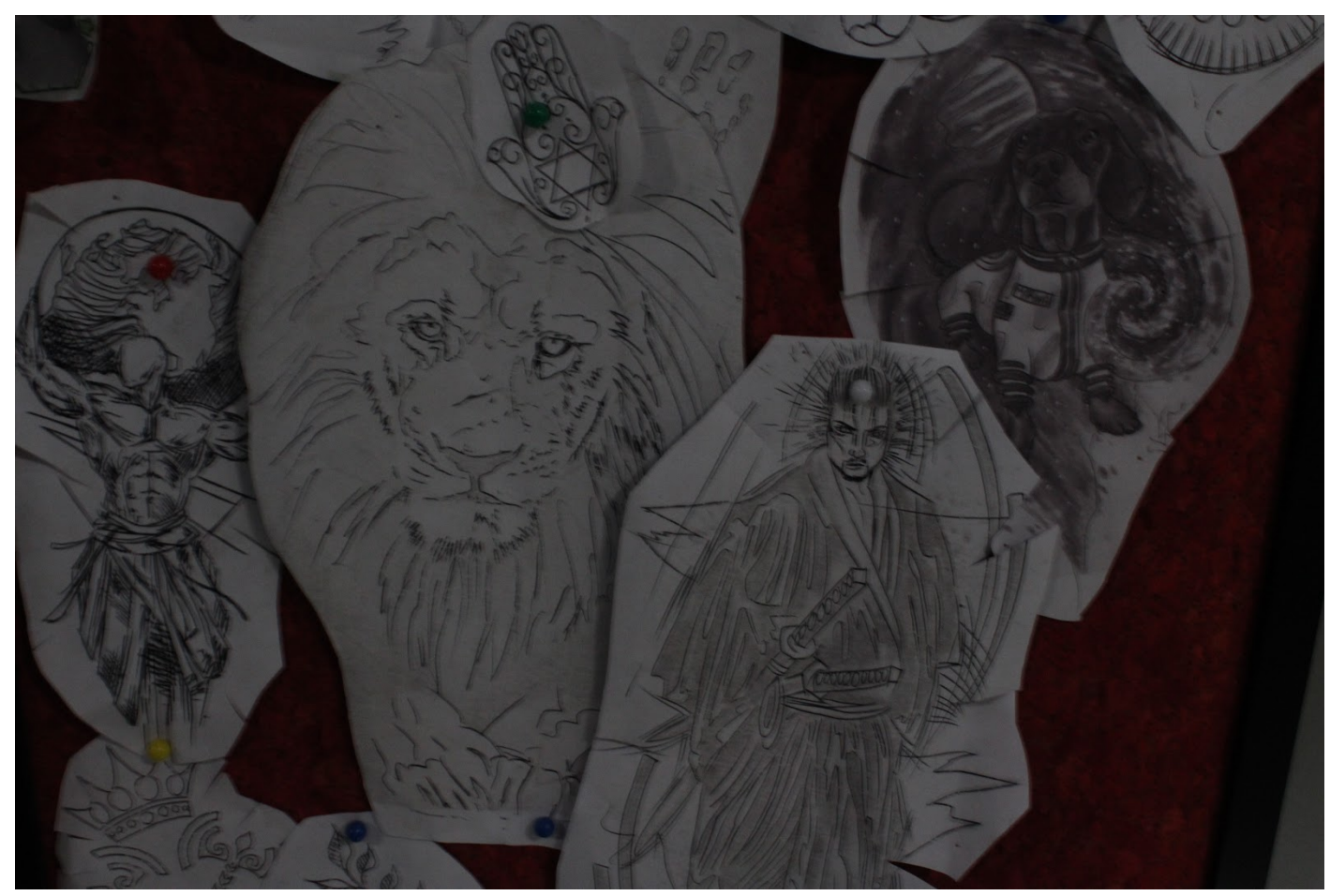

Fonte: Giovanna Dai-Prá (2020) - Mural de “carimbos" das tatuagens feitas.

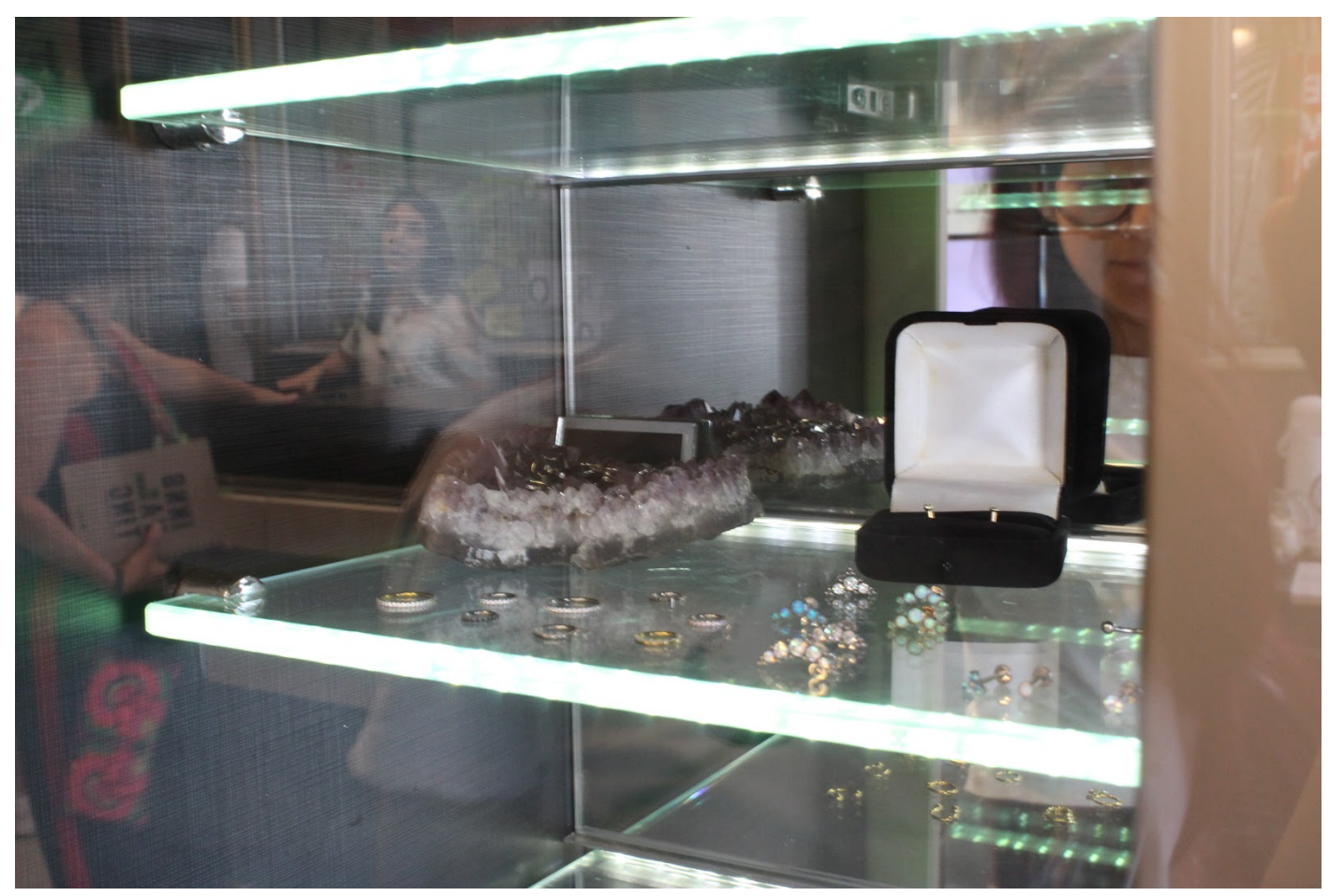

Fonte: Giovanna Dai-Prá (2020) - Vitrine com mostruários de piercing . .

Finalizada a conversa com a equipe do estúdio, foi decidido procurar depoimentos nos estabelecimentos vizinhos, sendo escolhido conversar com os membros de uma cafeteria e em seguida com os funcionários de um estúdio fotográfico 
que está na localidade há anos. Os dois ambientes mostraram essenciais na pesquisa de campo realizada, oportunizando depoimentos.

$\mathrm{Na}$ cafeteria, foram entrevistados o senhor Derli e sua esposa. Os dois relataram que a Tattoo Arte é uma referência no ramo de tatuagens na região e em Novo Hamburgo. O senhor Derli em determinado momento demonstrou-se emocionado ao falar do local, pois após passar por uma situação adversa em sua vida, ele registrou este momento de superação na pele alí, com os profissionais do estúdio de tatuagem. E ele finaliza seu depoimento reforçando que "a tatuagem é realmente uma arte", reafirmando a intencionalidade do nome dado ao estúdio, Tattoo Arte.

No estúdio de fotografia, entrevistamos a Simone e a Ana Paula. Simone não se sentiu muito confortável para participar, mostrando até um certo desinteresse pela pesquisa e preferindo dar a palavra à Ana Paula. Esta última foi mais receptiva e falou mais abertamente sobre como via a presença de seus vizinhos. Aos olhos de Ana Paula, o estúdio é diferenciado, pois, nas palavras dela: "não ficou na mesma, evoluiu" e completa dizendo "eu vejo eles fazendo umas movimentações, campanhas e a maioria das pessoas falam bem do trabalho deles". Relatou também, que mesmo a loja de fotografias ser mais antiga que o estúdio de tatuagem, por muitas vezes usou o estúdio como referência para que os clientes chegassem a loja delas.

Até o presente momento, com esses dois depoimentos é possível considerar que a fala dos vizinhos entrevistados vai ao encontro do diálogo com a Sabrina, gerente da Tattoo Arte. E diferente do que foi pressuposto quando iniciou-se a saída de campo, que seriam encontrados relatos de preconceitos e estranhamentos isso não ficou perceptível quanto às situações relatadas pelos depoentes. Percebendo como as entrevistas estavam ajudando a tecer um perfil do local de pesquisa, foi decidido buscar outros estabelecimentos e depoimentos. Retornando à galeria, foram avistadas uma ótica e uma barbearia, ambas de pequeno porte e que aparentavam estar há mais tempo no local do que as outras lojas. Foi decidido, porém, não adentrar os locais pois os dois estabelecimentos estavam em atendimento, deixando assim para fazer as entrevistas na próxima saída de campo.

Em todos os entrevistados, percebe-se que a admiração pelo trabalho do estúdio era muito clara, pois tinham uma visão bem diferenciada do que foi esperado. Apesar 
das alunas serem "fãs" de tatuagem, o esperado era encontrar relatos, impressões, histórias de preconceitos e receios, que acabaram sendo relatados demonstrando respeito, admiração, referência, organização, beleza, acolhimento e profissionalismo. $\mathrm{O}$ que surpreendeu, devido à carga de tradições que aquele espaço traz, diante de toda a construção do centro, e da Galeria Hamburguesa. Observa-se que a Tattoo Arte, conseguiu se adaptar às mudanças e evoluir, de forma que se tornou parte da história local, sem precisar colidir com a cultura, sem invalidar as ideias originárias que foram se desenvolvendo com o espírito inovador ao longo dos anos.

\section{História e Memória, os entrelaçamentos entre a Tatuagem e a Arte.}

Após realizada a primeira saída de campo, foi desenvolvida uma pesquisa histórica sobre a região em que se localiza o estúdio de tatuagem que serviu como objeto de estudo. Tendo em vista as observações realizadas anteriormente acerca do local escolhido para o trabalho de campo, percebe-se a importância dessa região dentro da cidade de Novo Hamburgo. Esse fato levanta o questionamento de que a rua David Canabarro e seu entorno contribuíram no desenvolvimento de Novo Hamburgo e que preservam parte da memória da cidade. Para isso, considera-se os estudos dos processos de desenvolvimento dos estágios culturais formulado por Boas e pela escola histórica, que valoriza a investigação sobre a distribuição geográfica e as causas históricas. Assim sendo, ratifica-se este entrelaçamento histórico, memorialístico e cultural uma vez que,

Os resultados das investigações conduzidas por esse método podem ser tríplices. Eles podem revelar as condições ambientais que criaram ou modificaram os elementos culturais; esclarecer fatores psicológicos que atuaram na configuração da cultura; ou nos mostrar os efeitos que as conexões históricas tiveram sobre o desenvolvimento da cultura. (Boas, 1896. In: Castro, 2005: 34).

Novo Hamburgo, até então $2^{\circ}$ distrito de São Leopoldo, conseguiu sua emancipação assinada por Borges de Medeiros em 5 de abril de 1927, possuindo uma área de $65 \mathrm{~km}^{2}$, uma população composta por 8.500 pessoas, e 1.438 prédios (Selbach, 1999). Para apagar o passado como distrito, buscou-se a modernização do território principalmente com a construção de novas ruas, com condições de receber os primeiros veículos automotores na cidade e que mudassem a imagem de uma região rural para uma região urbana e industrial. 
Além da ordenação do espaço, buscou-se uma "ordenação social" que resultou em uma forte separação étnica até o início dos anos 1940, separando o que era tido como "belo e agradável" do "restante", o que significou a divisão entre uma área de descendentes germânicos: Hamburgo Velho; uma área destinada ao comércio em geral: Novo Hamburgo; uma área, vulgarmente conhecida por 'África', onde ficava a população descendente de povos africanos; e o Mistura, onde ficavam os "brazilianers" (aqueles que tinham miscigenação) (Selbach, 1999).

A partir da década de 1950 começou-se a pensar os moradores vindos de outras cidades para trabalhar em Novo Hamburgo, além de criar-se um novo plano de urbanização focando nas variações e finalidades de cada espaço: rua de comércio, residências, área industrial, etc.; plano este que proveu aos poucos o crescimento vertical da cidade. Porém, é na década de 1970 que o desenvolvimento urbano e industrial chega ao seu auge, com o crescimento da indústria do calçado de forma a levar o município a ser considerado a capital nacional do calçado.

As ruas da pequena comunidade alemã, outrora de trânsito familiar, transformaramse. E a metamorfose maior ficou por conta de seu uso. A rua da antiga vila, usada como espaço cívico-religioso, desapareceu. A multidão miscigenada tomou conta do espaço urbano e carregou consigo o anonimato. Desprovidos de experiência, seus habitantes passaram à ver o choque inerente à cidade moderna. (Selbach, 1999: 52).

A rua David Canabarro têm sua importância para a sociabilidade da comunidade hamburguense e para o comércio local desde a década de 1930, principalmente devido à sua proximidade com a Avenida Pedro Adams Filho e com a Praça 14 de Julho (atual Praça do Imigrante). Nas décadas de 1930, 1940 e 1950, o trecho da avenida entre a rua Lima e Silva e a David Canabarro era fechada para descanso e socialização das famílias nos domingos. Já na década de 1970, a esquina da David Canabarro com a Avenida Pedro Adams Filho ficou conhecida como espaço de encontro entre os jovens. 


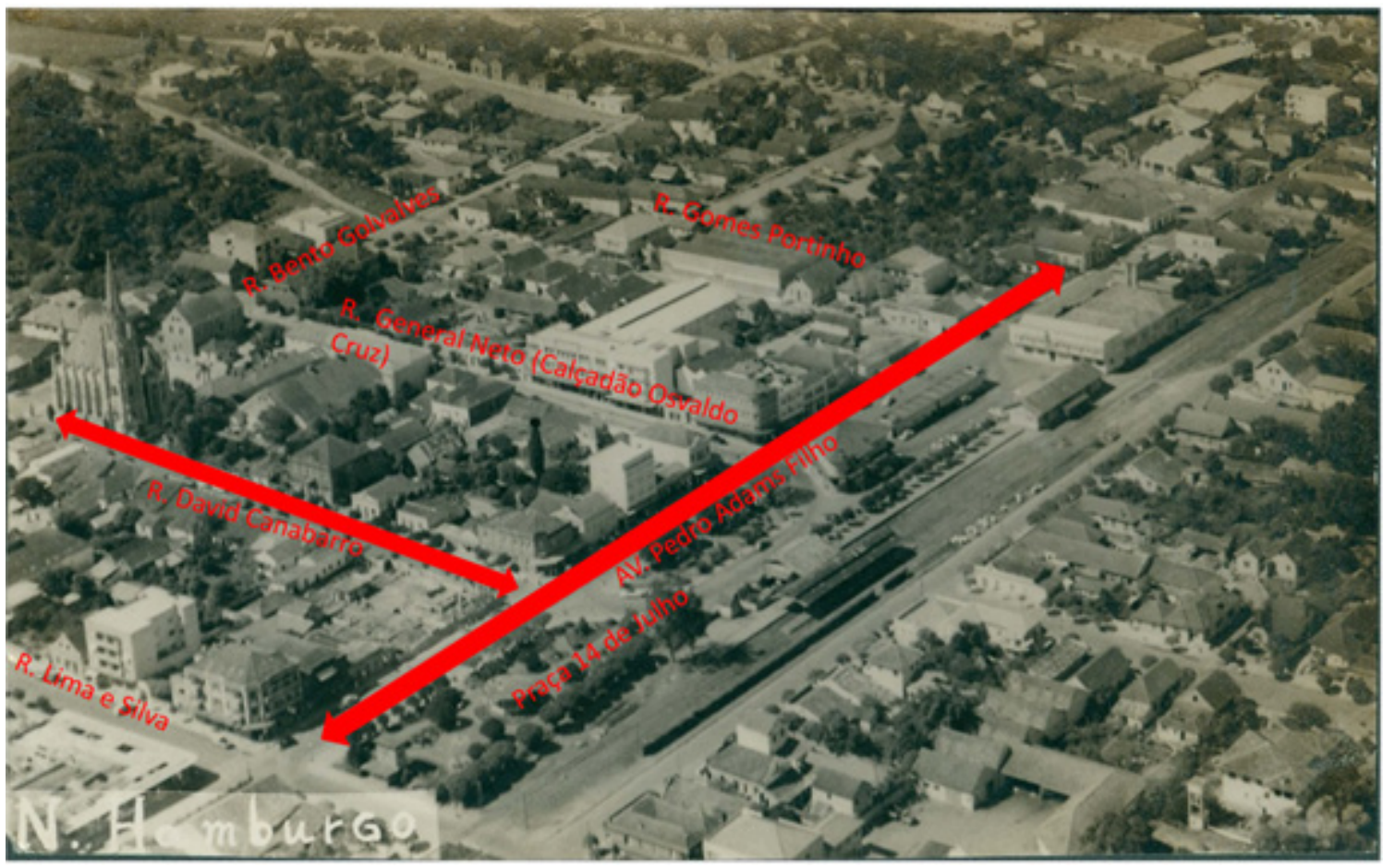

Novo Hamburgo - Centro. Ano não informado. Fonte: Biblioteca do IBGE. Disponível em: $<$ https://biblioteca.ibge.gov.br/index.php/biblioteca-catalogo?view=detalhes\&id=444775>

A Galeria Hamburguesa (Rua David Canabarro) foi criada copiando as chamadas "passagens" da Paris do século XIX: centros comerciais de mercadorias de luxo. Novo Hamburgo introduziu as primeiras galerias em seu espaço urbano na década de 1970, como sinônimo de progresso e modernização. Esses locais reuniam lojas de variados ramos comerciais e buscava expandir o espaço comercial da região, que vinha sendo limitado pelo crescimento da cidade. Quando construída, a Galeria Hamburguesa, uma das primeiras, possuía 38 lojas térreas e 17 no piso superior, com relojoarias, lojas de roupa, móveis, óticas, consultórios, lancherias entre outros estabelecimentos.

Em vista das características da formação da cidade, é perceptível que Novo Hamburgo foi amparada por uma colonização alemã conservadora e pela expansão da indústria calçadista. A comunidade Hamburguense moldou de forma invisível e pragmática os "parâmetros" culturais da sociedade atual. Portanto, sendo a cidade em questão um "objeto de múltiplos discursos e olhares, que não se hierarquizam, mas que se justapõem, compõem ou se contradizem, sem por isso serem uns mais verdadeiros ou importantes que os outros." (Pesavento, 1999: 09), lança-se um olhar micro para um estabelecimento específico - Tattoo Arte - dessa mesma sociedade a fim de 
investigar/analisar, através do trabalho de campo, como, e de que forma os constructos sociais e culturais foram se entrelaçando na construção e na constituição do estabelecimento enquanto ambiente produtor de arte.

\section{O tracejado Ink como fio condutor da Arte na pele}

Com a primeira saída de campo, foram coletadas muitas informações sobre o estúdio, sobre o perfil dos clientes, e sobre a relação entre o estúdio e os outros estabelecimentos presentes na mesma rua. O objetivo seguinte era fazer uma nova saída à campo para observar novamente o estúdio, observar mais a rua e realizar novas entrevistas em outros estabelecimentos, mas, devido à pandemia do Covid-19, foi possível apenas realizar a entrevista com o Éder, proprietário da Tattoo Arte, que focou em relatar a sua trajetória como tatuador e também sobre seu estúdio, que permanece há 22 anos na mesma localização.

A fronteira invisível imposta pela pandemia do Covid-19, inviabilizou a realização do encontro presencial com o proprietário do estúdio de tatuagem e por este motivo a entrevista foi realizada via videoconferência, no dia 06 de março de 2020, através do aplicativo do WhatsApp. A entrevista foi gravada, garantindo o máximo de dados possíveis, através de aplicativo para celular. Após fazer a apresentação sobre o trabalho ao Éder, foi solicitado que ele relatasse como tudo começou e que tentasse fazer um panorama histórico da sua trajetória, momentos importantes e essenciais para chegar até onde chegou o seu trabalho.

Éder, apresentava-se confortável, e começou a explanar suas lembranças da infância, de como ele gostava de desenhar, e como trocava trabalhos da disciplina de artes com seus colegas na escola, por merenda. Aos 12 anos, Éder que chegou a jogar na escolinha do Grêmio, rompeu o ligamento do o joelho andando de bicicleta e assim, ficou impossibilitado de voltar a jogar, carreira estimada pelo pai e ex-jogador de futebol. Logo os colegas de seu pai, viram nele uma carreira promissora na área de modelista, por conta da qualidade de seus desenhos, na qual Éder achava que ficaria muito "preso", uma vez que gostava de desenhos livres. Mesmo sendo preparado para uma cultura da valorização do trabalho "tradicional", com salário estipulado e carga horária estabelecida, Éder vislumbrava por algo que pudesse trazer valor e 
significado para a vida dele, sentimento que vai ao encontro da fala de Roy Wagner em entrevista a Fapeam:

[...] O que a da vida? O que a ânimo? O que dá alma? O que é dinheiro sem alma e sem vida? É a vida do dinheiro que lhe dá valor, lhe dá significado. Se não houver vida no dinheiro, não houver alteridade a vida perde o valor. Então, você se torna um proletário sem sentido na vida, como no no livro "1984" de George Orwell. (Wagner, R. Disponível em: <https://www.youtube.com/watch?v=IDdYbumrgcA>. Acesso em: 15 de abr. 2020)

Entretanto, durante um determinado período foi obrigado a aderir a forma tradicional de trabalho por meio de uma oportunidade adquirida pela interferência do seu pai, que trabalhava na prefeitura e, conseguiu um emprego para ele na farmácia comunitária, onde inicia seu trabalho para ajudar em casa.

Éder relata que um primo, decide fazer uma tatuagem e pede que ele o acompanhe, ambos com 13 anos, e foi neste momento que despertou a vontade de ser tatuador. Decidiu então guardar o dinheiro que recebia da mãe para lanches, sorvetes e saídas, e assim conseguir pagar sua primeira tatuagem, que custará R \$65,00 (sessenta e cinco reais). No entanto, no momento em que era tatuado, observou um cartaz que divulgava sobre um curso de tatuagem, no valor de $\mathrm{R} \$ 300,00$ (trezentos reais). Porém, percebe-se envolvido em duas situações que teria que enfrentar, a primeira, contar para seus pais que fez uma tatuagem, e a segunda, era sobre a sua intenção de realizar o curso e se profissionalizar como tatuador. Tendo em vista que sua família se enquadra no modelo tradicional de "origem alemã", Éder acreditava que seus pais não permitiriam que seguisse essa profissão, vista como "flutuante", ao invés da de modelista considerada "estável".

No momento que contou aos seus pais que fizera uma tatuagem, também demonstrou o seu desejo de se profissionalizar em tatuagem. Seus pais, por sua vez, aceitaram que ele fizesse o curso, no compromisso de organizar sua agenda diária, continuando a trabalhar pela manhã na farmácia, à tarde faria o curso de tatuagem, e a noite tatuaria em casa. Para obter o dinheiro que custearia a compra do seu material de trabalho para que assim pudesse começar a atender sua clientela, opta por vender uma bicicleta que ele tinha ganho de natal, a mesma foi vendida, escondido dos pais.

Durante 6 meses seu estúdio era em casa, atendendo amigos e parentes, até que seu antigo professor, o convidou para um estágio no estúdio de tatuagem, suspendendo 
suas atividades na farmácia onde trabalhava. Logo percebeu que tinha uma renda fixa muito mais vantajosa. Posto que, por meio turno na farmácia ele recebia um valor de $\mathrm{R} \$ 180,00$ (cento e oitenta reais), e com a tatuagem chegava a ganhar até quinze vezes mais. Com um ano de trabalho, conseguiu comprar seu primeiro carro, aos 16 anos. Logo ganhou segurança, e começou a assumir a agenda do seu professor, porém com um certo tempo, o professor percebeu que poderia reassumir sua agenda, e assim ganhar o dinheiro que estava sendo pago para eu aprendiz. Naquele momento, decidiu demitir Éder, que se encontra repleto de dívidas. Diante desta nova realidade, seus pais decidiram ajudar a abrir um estúdio.

Sua mãe, que tinha um ateliê de costura, vendeu uma de suas máquinas que, no valor de hoje, seria em torno de 20.000,00 (vinte mil reais), para ajudar com na montagem do estúdio. O pai, alugou uma sala já na Galeria Hamburguesa, localizada no meio da galeria, onde começou a Tattoo Arte, no inverno de 1998. Depois deste primeiro movimento dos pais ele toma frente das responsabilidades financeiras e de toda logística do empreendimento.

Dois anos depois, o seu ex professor, fecha o estudo em Novo Hamburgo e vai trabalhar com tatuagem em Porto Alegre, com isso, Éder recebe toda agenda de clientes. Passado um ano, este ex professor entra em contato novamente, desta vez comentando que estará de volta a Novo Hamburgo e que gostaria de trabalhar com ele na Tattoo Arte. Porém, por ter um espaço limitado, e por perceber que não poderia acolher quem havia lhe dado a primeira oportunidade de estágio, e também seus clientes, decidiu arriscar e investir, e como disse o mesmo: dar um "chute na lua", alugou a sala ao lado, e assim foram administrando em parceria com um terceiro amigo, responsável pelo setor de piercings. E a partir deste momento a Tattoo Arte desenvolveu a sua marca.

Éder também relatou acontecimentos do início de sua carreira: "Foi o preconceito que me fez chegar onde estou hoje”. Quando circulava na cidade com tatuagens aconteciam situações, como por exemplo, de senhoras passarem do lado e fazer o sinal da cruz, nos restaurantes as pessoas ficavam olhando e se cutucando, nas festas, muitas vezes as pessoas se dirigiam aos colegas na conversa e a ele não. A "roupagem" de Éder e as situações de estranhamento vividas por ele coadunam com a reflexão feita por Viveiros de Castro, tendo em vista que, 
Os animais que tão com uma roupa, o corpo animal é visto como uma espécie de roupa que esconde um fundo humano, uma alma humana, e que em certas situações específicas, o animal se revela como gente. Essas são as situações perigosas. Assim como para nós, quando o homem mostra seu lado animal, em geral não é no bom sentido. (Viveiros de Castro. Disponível em: $<$ https://www.youtube.com/watch? $\mathrm{v}=\mathrm{eSrJcwnqOt4}>$. Acesso em 15 de abr.2020).

Para os familiares, que moram no interior de Rolante, o indivíduo com tatuagem e sem dinheiro era visto como marginal. E Éder constata que como sujeito de uma sociedade que valorizava e valoriza até a contemporaneidade a pessoas a partir de sua classe social, bens, e representação estética padronizada, que ele não se enquadrava nesses quesitos e que portanto, não era valorizado principalmente por não ter absolutamente nada, como ele mesmo aponta: "Eu não tinha nem uma bicicleta pra andar".

Movido pela paixão pela tatuagem, mas também pela busca incessante por respeito e aceitação da sociedade hamburguense, Éder exemplifica o que a seu ver seria uma das formas de obter o tão sonhado reconhecimento:

[...] eu tinha na minha cabeça, eu vou mudar o mundo da tattoo em Novo Hamburgo, eu vou mudar o mundo da tattoo no Rio Grande do Sul. Naquela época eu disse, eu quero ter uma caminhonete pra chegar, e as pessoas olhares assim, óh... por que as pessoas iam me olhar e não iam mais me julgar, na minha cabeça era isso.

O constructo cultural e social emoldurado pela coletividade de Novo Hamburgo e região edificou uma concepção fundamentada na força da economia e todos os benefícios e malefícios a ela atribuídos aos sujeitos desse corpo social. Observa-se essa composição a partir da fala do Éder ao mencionar que era preciso, "ter para mostrar que a tattoo também pode”, ou seja, é preciso ter para ser. Esse pensamento não se restringe somente a sociedade hamburguense, mas de forma geral a sociedade como um todo, porém o enredo atual estabelecido através da pandemia do Covid-19 evidencia que,

[...] uma economia não é nada ao menos que tenha vida, tem que haver algo que vitalize o dinheiro; que traga o dinheiro para a vida. Da mesma maneira, uma pessoa, uma cultura, uma universidade ou uma nação, precisam ser vitalizadas. Não estou falando de investimentos, estou falando de invenção! (Wagner, R. Disponível em: $<$ https://www.youtube.com/watch? v=IDdYbumrgcA $>$. Acesso em: 15 de abr. 2020.

Tendo a consciência de que o capital já orientava o cerne social e que, para elevar a tatuagem e seus simbolismos, era preciso ter para sair da margem e ser visto, Éder construiu sua história entrelaçada ao estúdio. Diante da realidade descrita, empenhou-se fortemente em divulgar seu trabalho como tatuador através de folhetos de restaurantes e pequenas revistas, sempre associando a própria imagem à Tattoo Arte. 
Realizando inicialmente um trabalho de "porta a porta", lançou metas mais promissoras: aspirando uma visibilidade maior, anunciou seu trabalho em uma revista renomada na região, buscando colocar a profissão de tatuador no mesmo patamar do arquiteto, do engenheiro e do médico, público alvo da revista.

Com intuito de profissionalizar e visibilizar cada vez mais a empresa Tattoo Arte e a própria tatuagem como uma forma de arte, Éder passou a realizar treinamentos com sua equipe e ministrar cursos de tatuagem em Novo Hamburgo, inicialmente, e na região. Conforme foi obtendo a visibilidade sonhada, investiu na realização de cursos no exterior. Atualmente possui um projeto em andamento para trabalhar em um estúdio de tatuagem nos USA, buscando assim expandir seu trabalho e futuramente criar uma filial americana.

\section{Considerações Finais}

A partir das ideias apresentadas pelos teóricos deste estudo e pela interferência pessoal de cada sujeito presente neste trabalho etnográfico, configurou-se uma possível leitura sobre as intervenções culturais e sociais ocasionadas entre o estúdio de tatuagem e a comunidade hamburguense. Ao buscar compreender as relações estabelecidas entre um ponto específico da cidade e o resto da comunidade, percebe-se uma construção cultural com ramificações em diversas problemáticas sociais.

$\mathrm{O}$ anseio por aproximar a tatuagem da arte, por reconhecimento e profissionalismo, provoca elucubrações sobre o que é considerado cultura na sociedade atual, sobre a supervalorização de determinados processos culturais em detrimento de outros. Uma vez que, uma parcela considerável da sociedade não cultua e nem vivencia a "cultura erudita", mas busca respaldo nela para reformular e reafirmar os seus ideais já preestabelecidos. Como afirma Arantes (2006), as diferenciações entre erudito (ou culto) e popular são compreensões etnocêntricas e autoritárias, que tornam certos valores e concepções mais legítimos do que outros ao serem implementados socialmente através instituições que servem como meios de divulgação de ideias, são exemplos as escolas, igrejas e meios de comunicação. Algumas manifestações culturais 
são esvaziadas, espezinhadas, somente pelo fato de não pertencerem aos grupos sociais dominantes.

A etnografia de rua oportuniza uma série de questionamentos tanto pra quem é etnografado quanto para quem faz o trabalho etnográfico. Propor-se a conhecer o outro e as suas nuances nem sempre apresenta um caminho inteligível. A escolha do espaço, das pessoas e dos métodos, bem como as diferentes vivências e experiências culturais do grupo que pesquisa, produzem divergências, afastamentos pontuais no âmbito social e cultural, como também une e transforma os sujeitos engajados no processo etnográfico. Com base nessas considerações constata-se que o amparo interdisciplinar permite a realização de um estudo com diferentes olhares e possíveis análises acerca das manifestações culturais, pois, para além dos estudos antropológicos, as experiências traçadas com o método etnográfico torna-se possível a tessitura entre diferentes áreas do conhecimento.

\section{REFERÊNCIAS}

ARANTES, Antônio. A. O que é Cultura Popular. São Paulo: Brasiliense, 2006

BITTENCOURT, Luciana. A fotografia como instrumento etnográfico. In: Anuário Antropológico/ 92. Rio de Janeiro: Tempo Brasileiro, 1994. Disponível em: < http://www.dan.unb.br/images/pdf/anuario_antropologico/Separatas1992/anuario92_luc ianabittencourt.pdf>. Acesso em: 20 mai. 2020.

BOAS, Franz. As limitações do método comparativo em Antropologia. In: CASTRO, Celso (Org.). Antropologia cultural. Rio de Janeiro: Jorge Zahar Ed. 2005. P.25-40

FOOTE-WHYTE, William. Treinando a observação participante. In: GUIMARÃES, Alba Z. Desvendando máscaras sociais. Rio de Janeiro: Editora Francisco Alves, 1990. cap. 3, p 77-86.

PESAVENTO, Sandra J. O imaginário da cidade - Visões literárias do urbano. Porto Alegre: Editora da UFRGS, 2002. 400 p. 
SELBACH, Jeferson F. Novo Hamburgo 1927-1997: os espaços de sociabilidade na gangorra da modernidade. Dissertação de Mestrado - UFGS-PPG em Planejamento Urbano e Regional - PROPUR. Porto Alegre, 1999.

VELHO, Gilberto. O antropólogo pesquisando em sua cidade: sobre conhecimento e heresia. In: . O desafio da cidade: novas perspectivas da antropologia brasileira. Rio de Janeiro: Campus, 1980. P.13-23.

VELHO, Gilberto; VIVEIROS DE CASTRO, Eduardo. O conceito de cultura e o estudo das sociedades complexas: uma perspectiva antropológica. Artefato: Jornal de Cultura, ano 1, n. 1, 1978.

VIVEIROS DE CASTRO, Eduardo. Perspectivismo e centros de consciência.

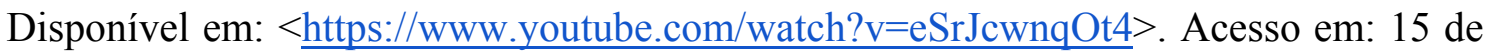
abr. 2020.

WAGNER, Roy. A invenção da cultura. São Paulo: Ubu Editora, 2017.

WAGNER, Roy. FAPEAM: Entrevista Roy Wagner. Disponível em:

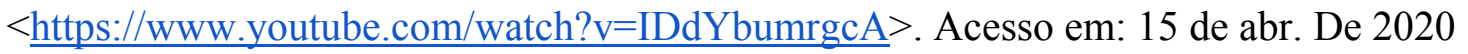

Recebido: 29/06/2020

Aprovado: 04/09/2020 